\title{
Loneliness as a risk factor for frailty transition among older Chinese people
}

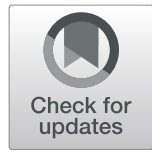

Sha Sha', Yuebin $\mathrm{Xu}^{2}$ and Lin Chen ${ }^{2,3^{*}}$ (D)

\begin{abstract}
Background: Previous literature has reported that loneliness is a strong predictor of frailty risk. However, less is known about the role of loneliness in frailty transition types. This study aimed to examine whether and how Ioneliness are related to frailty transition among older Chinese people.

Methods: Our study used participants (aged $\geq 60$ years) from 2008/2009, 2011/2012 and 2014 waves of the Chinese Longitudinal Healthy Longevity Survey (CLHLS). Loneliness was assessed by a single question asking how often the respondent feels lonely. The FRAIL Scale was created to measure physical frailty for our study, and frailty was also assessed by a broader definition of the frailty index. Frailty transition as an outcome variable has been designed as two types according to the measurement of frailty.

Results: Greater loneliness at baseline reduced the possibility of remaining in a robust or prefrail physical frailty state after 3 years $(\mathrm{OR}=0.78,95 \% \mathrm{Cl}: 0.68-0.91, p<0.01)$. Greater loneliness was associated with an increased risk of worsening physical frailty over time: compared with those who had never felt lonely, the odds ratios for people who often felt lonely were 1.19 (95\%Cl: 1.01-1.41, $p<0.05$ ) after 3 years and 1.34 (95\%Cl: 1.08-1.66, $p<0.01)$ after 6 years. The association between loneliness and change in the frailty index differed in the survey periods: loneliness at baseline was found to increase the possibility of participants remaining in frailty (seldom loneliness: $\mathrm{OR}=1.78$, 95\%Cl: 1.25-2.55, $p<0.01$; often loneliness: $\mathrm{OR}=1.74,95 \% \mathrm{Cl}: 1.21-2.50, \mathrm{p}<0.01$ ) after 6 years, but no significance was shown in the 3-year follow up. Additionally, loneliness at baselines was significantly associated with frailty transition at follow up among the male participants. However, a similar association was not observed among the female participants.
\end{abstract}

Conclusion: Older people with a high level of loneliness tend to be frail in the future, and greater loneliness is related to an increased risk of worsening frailty and remaining frail. Male elderly with a high level of loneliness were more likely to have a worse frailty transition than female elderly in China.

Keywords: Loneliness, Frailty, Frailty transition, Longitudinal, Older people, Gender difference

\footnotetext{
*Correspondence: linchen_988@163.com

${ }^{2}$ Institute of advanced Studies in Humanities and Social Sciences, Beijing

Normal University at Zhuhai, Zhuhai 519087, China

${ }^{3}$ International Business Faculty, Beijing Normal University, Zhuhai 519087,

China

Full list of author information is available at the end of the article
}

(c) The Author(s). 2020 Open Access This article is licensed under a Creative Commons Attribution 4.0 International License, which permits use, sharing, adaptation, distribution and reproduction in any medium or format, as long as you give appropriate credit to the original author(s) and the source, provide a link to the Creative Commons licence, and indicate if changes were made. The images or other third party material in this article are included in the article's Creative Commons licence, unless indicated otherwise in a credit line to the material. If material is not included in the article's Creative Commons licence and your intended use is not permitted by statutory regulation or exceeds the permitted use, you will need to obtain permission directly from the copyright holder. To view a copy of this licence, visit http://creativecommons.org/licenses/by/4.0/ The Creative Commons Public Domain Dedication waiver (http://creativecommons.org/publicdomain/zero/1.0/) applies to the data made available in this article, unless otherwise stated in a credit line to the data. 


\section{Background}

Populations worldwide are rapidly aging, which presents a particularly severe challenge in China, a country where the population is aging at a significantly faster rate than other low- and middle-income countries [1]. According to data published by the National Bureau of Statistics of China, $17.3 \%$ of the total population were aged 60 years and older in 2017. However, due to the implementation of the one-child policy in the earlier decades and recent increasing population mobility, the family size in China has been declining substantially, leading to over $50 \%$ of the urban and $60 \%$ of rural elderly living in empty-nest households, and the proportion of older people living alone in China was $12.5 \%$ in 2010 , an increase by $30 \%$ in the prior two decades [2,3]. These findings all have important implications for the health and social care of the elderly.

Frailty is the most outstanding expression of population aging [4]. It is a syndrome that predicts vulnerability to adverse outcomes and is recognized as a dynamic state with the potential for reversibility [4-7]. There are currently two major models of frailty: first, the frailty phenotype model that views frailty from the physiological systems and defines frailty as several biological syndromes [8]; second, the frailty deficit model measures frailty as problems resulting from a multidimensional system, including biological, physiological and psychological [9]. Despite a sizeable literature on the adverse outcomes of frailty, such as falls [10], disability [11, 12], hospitalization [13], institutional care [14, 15], and mortality [16-18], relatively little is known about the transition of frailty in older people. Although frailty is inevitable with increasing age [19], it is not irreversible but agreeable to be a dynamic process involving improvement and natural procession [4].

Loneliness is a common and dissatisfaction feeling of one's social relationship that is presently becoming a serious public health issue for older people [20, 21]. Loneliness has been observed to be associated with subsequent adverse outcomes, such as mortality [22, 23], comorbidity $[24,25]$, poor functional ability [26, 27], depression [28], and cognitive decline [29]. At the biological level, many studies have found that the feeling of loneliness is associated with increased blood pressure [30, 31], increased risk of cardio-cerebrovascular and inflammatory diseases [32-34], impaired immune function [35], and increased likelihood of sarcopenia [36].

Frailty, defined by the phenotype model or frailty index, is associated with loneliness [37-39]. A crosssectional study of Mexican community-dwelling elderly found that loneliness was independently associated with frailty [37]. The cohort study discovered that the relationship between frailty and loneliness might be bidirectional: loneliness was related to the change in frailty status, and vice versa $[38,40]$. However, studies on the association between loneliness and frailty were focused on loneliness and frailty risk, and none have specified the association between loneliness and frailty transition types, including remaining frail, worsening or improving in frailty status. Furthermore, the existing research was based mostly on western society; much less is known for older people in other studies.

A study of Chinese older adults had reported that 51.2 and $7.0 \%$ of older adults aged 60 years and older were prefrail and frail, respectively [41]. However, little research exists on frailty transitions in China. It was reported that about $30.4 \%$ of participants had transitioned between different frailty statuses in 2002-2005 [42]. Additionally, one study showed that loneliness was related to culture and social policies [43]. People from collectivist cultures are more likely to feel lonely [44]. It was reported that about $30 \%$ of Chinese older adults reported feelings of loneliness [45]. We speculated that loneliness could have more influence on frailty transition in China. Gender difference in frailty and loneliness is well known [46, 47]. Women tend to have a higher incidence of frailty than men $[48,49]$, and it was suggested that this might be attributable to both biological and socioeconomic factors [50]. Studies have shown that loneliness is strongly associated with adverse health conditions in men and women $[51,52]$. Thus, it can be assumed that the association between loneliness and frailty transitions is gender related.

Our study aimed to examine the association between loneliness and frailty transition among older adults older than 60 years in China. We generated two hypotheses: 1) loneliness is related to frailty transition, and 2) the relationship between loneliness and frailty is different by gender. We believe that our study would help to close the gap in the existing literature by using a nationally representative longitudinal sample in China, and the results would also be useful in informing policy making in health and social care.

\section{Method}

Data

The data came from the Chinese Longitudinal Healthy Longevity Survey (CLHLS), which is the first and largest nationwide longitudinal survey in China. The survey is designed to investigate the determinants of the health and longevity of older adults in China. Thus far, information has been collected in half of the randomly selected cities/counties in 23 of 31 provinces in China, with a total of 113,000 households being interviewed. The CLHLS was initiated in 1998, and follow-up interviews were conducted in 2000, 2002, 2005, 2008/2009, 2011/2012, 2014 and 2017/2018 [53]. The questionnaire contained information about demographics, lifestyle, 
diet, self-reported health, psychological health, activities of daily living (ADL) and instrumental activities of daily living (IADL). The rationales, more details of the survey design, and data quality were published elsewhere [54].

Our study utilized the participants of CLHLS in 2008/ 2009, 2011/2012 and 2014 to conduct two cohorts. Briefly, among the 16,840 participants (aged $\geq 60$ years) in $2008 / 2009,2782(17 \%)$ were lost to follow up and 5633 (33\%) died before the 2011/2012 survey. We excluded those lost to follow-up due to their unknown information and removed those who died before the follow-up to eliminate the effect of mortality. Finally, a valid sample size of 8425 participants was analyzed for the 3-year follow-up period (2008-2011). Among the 16, 840 participants (aged $\geq 60$ ) in 2008/2009, 8415 (50\%) died or were lost to follow up in the 2008-2011 waves, 591 (4\%) were lost to follow up in the 2014 survey and 2589 (15\%) died before the 2014 survey. In total, 5245 (31\%) participants were alive for analysis for the 6-year follow-up period (2008-2014). The flowchart of the study is shown in Fig. 1.

\section{Measures}

\section{Loneliness}

Loneliness was measured with a single question asking how often the respondent feels lonely. The 5-point response scale ranged from "never" to "always". Singleitem questions are sometimes known as self-rating measures of loneliness because they can ask directly for the individual's assessment of how lonely they feel. The single question of loneliness has been used widely [55-57] and has proven to be valid and highly correlated with multi-item loneliness scales $[58,59]$. Because the question on loneliness in CLHLS is highly skewed with fewer respondents in the "always" and "often" categories, we classified "sometimes", "often" and "always" into one category and "seldom" and "never" into another category to show the level of loneliness.

\section{Frailty status}

The FRAIL Scale [60] was created to measure physical frailty for our study. It comprises 5 simple questions to assess the presence of fatigue, muscle resistance, aerobic capacity, disease burden, and weight loss [61]. Those who met three or more components were defined as frail, those with 1 or 2 components were deemed as prefrail, and those without any were defined as robust $[60,62]$. Based on the CLHLS questionnaire design, we made some adjustments to the FRAIL Scale indicators. Each item in the FRAIL Scale was dichotomized and mapped to the interval $0-1$. Fatigue was measured using the question of "Do you feel the older you get, the more useless you are?" The analysis codes "never", "seldom", and "sometimes" as 0 and 1 otherwise. Resistance was measured as "Can you continuously crouch and stand up three times?" and ambulation as "Can you walk continuously for 1 kilometer at a time by yourself?". For the two variables, the analysis recodes 0 for "without assistance" and 1 otherwise. Illness was measured by selfreporting more than 5 types of illness and was coded as 1. Loss of weight was measured by BMI (weight (in kilograms)/height (in meters) ${ }^{2}$ ) using the same cutoff points of underweight $(<18.5)$.

Our study also used another model of the frailty index to measure the dimensions of frailty, in which at least 30 deficits are needed [63]. We used 37 indicators of various dimensions of the frailty status, coded as 1 when the deficits occurred and 2 if the respondents had a serious illness that caused him/her to be hospitalized or bedridden two or more times $[18,64,65]$. A high value in the

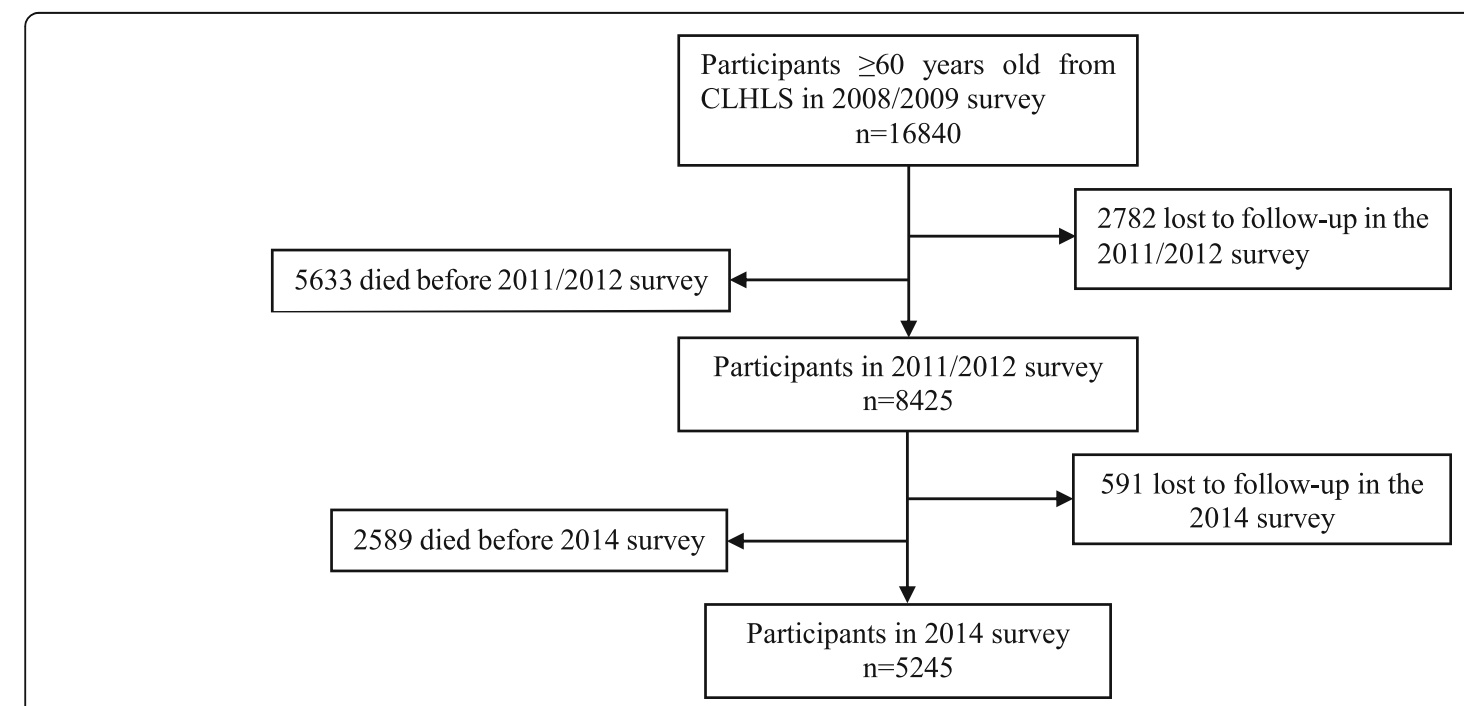

Fig. 1 Flow diagram of participants 
frailty index indicated poorer frailty. We also classified the continuous frailty index into nonfrail $(\mathrm{FI} \leq 0.21)$ and frail (FI $>0.21$ ) based on previous studies [42,66]. A full description of the frailty index can be found in Table 1 .

\section{Frailty transitions}

The change in frailty status between 2008 and the follow up in 2011 and 2014 was used as the outcome. Frailty transitions were created as two types in our study because we used two frailty models.

Four transitions between the physical frailty states were designed in our study according to the Frail Scale: remaining robust or prefrail, indicating that the elderly have remained healthy to some extent; improvement, indicating improvement or a change from prefrail to robust or from frail to robust or prefrail; worsening, indicating a transition to greater frailty; and remaining frail, indicating that the elderly have remained unhealthy.

The change types in the frailty index were classified into four categories: remaining nonfrail, indicating that the frailty index of the elderly was under 0.21 during the period; worsening, indicating that the frailty index of the elderly had changed from nonfrail to frail; improvement, indicating that the frailty scores declined to nonfrail in the follow-up year; remaining frail, indicating that the frailty index remained frail in follow-up.

\section{Covariates}

Covariates were measured at baseline and included age, gender, living arrangement, residential area, education, relative economic status, smoking, drinking alcohol and the baseline physical frailty state.

Living arrangement was coded as 0 if participants were living independently and 1 otherwise. The residential area was commonly used in studies about China because urban and rural areas differ greatly in socioeconomic development [67]. The participants were asked about their years of education, which is used as a continuous variable in our study. The relative economic status was measured with the question: "How do you rate your economic status compared with others in your local area?". The response was classified into three categories and we reverse-coded them so that higher categories indicated higher economic status $(1=$ poor; $2=$ so so; $3=$ rich). The frailty transition between frailty states was highly dependent on the preceding frailty state [5], and the baseline frailty states were viewed as the number of components of the frail scale present in the baseline.

\section{Analytical sample}

In the 3-year period, 8425 participants were included in the 2008-2011 waves. The analysis of loneliness with frailty transition was based on 5746 (68\%) re-interviewed participants with completed data. The analysis of frailty
Table 1 List of items included in a frailty index

\begin{tabular}{|c|c|}
\hline NO. & Items \\
\hline 1 & ADLs: needs assistant in bathing \\
\hline 2 & ADLs: needs assistant in dressing \\
\hline 3 & ADLs: needs assistant in toileting \\
\hline 4 & ADLs: needs assistant in indoor transferring \\
\hline 5 & ADLs: needs assistant in continence \\
\hline 6 & ADLs: needs assistant in eating \\
\hline 7 & IADLs: unable to visit neighbors by himself/herself \\
\hline 8 & IADLs: unable to go shopping by himself/herself \\
\hline 9 & IADLs: unable to cook a meal by himself/herself \\
\hline 10 & IADLs: unable to wash clothing by himself/herself \\
\hline 11 & $\begin{array}{l}\text { IADLs: unable to walk continuously for } 1 \mathrm{~km} \text { at a time } \\
\text { by himself/herself }\end{array}$ \\
\hline 12 & IADLs: unable to lift a weight of $5 \mathrm{~kg}$ \\
\hline 13 & IADLs: unable to continuously crouch and stand up three times \\
\hline 14 & IADLs: unable to take public transportation by himself/herself \\
\hline 15 & Cognitive impairment (based on Mini Mental State Examination) \\
\hline 16 & Poor self-reported health \\
\hline 17 & Health state compared to past year \\
\hline 18 & Poor interviewer-rated health \\
\hline 19 & Vision loss \\
\hline 20 & Psychological distress (based on usefulness, fearfulness) \\
\hline 21 & Number of serious illnesses in the past 2 years ${ }^{a}$ \\
\hline 22 & Suffering from hypertension \\
\hline 23 & Suffering from diabetes \\
\hline 24 & Suffering from heart disease \\
\hline 25 & Suffering from stroke or cerebrovascular disease \\
\hline 26 & Suffering from bronchitis, emphysema, pneumonia, asthma \\
\hline 27 & Suffering from tuberculosis \\
\hline 28 & Suffering from cataract \\
\hline 29 & Suffering from cancer \\
\hline 30 & Suffering from Parkinson's disease \\
\hline 31 & Suffering from arthritis \\
\hline 32 & Suffering from dementia \\
\hline 33 & Functional limitations: unable to put hand behind neck \\
\hline 34 & Functional limitations: unable to put hand behind lower neck \\
\hline 35 & Functional limitations: unable to raise arm upright \\
\hline 36 & Functional limitations: unable to stand up from sitting in a chair \\
\hline 37 & Functional limitations: unable to pick up a book from floor \\
\hline
\end{tabular}

index change was based on 5618 (67\%) re-interviewed participants with completed data.

In the 6-year period, 5245 participants were included in the 2008-2014 waves. The analysis of loneliness with frailty transition was based on 3548 (68\%) participants with completed data by re-interviewed participants. The 
analysis of the frailty index change was based on 3288 (63\%) participants with completed data among reinterviewed participants.

\section{Method of analysis}

Descriptive statistics at baseline were summarized using means ( \pm standard deviation) or counts (percentages). Logistic regression was used to derive the odds ratios of loneliness for the physical frailty transition types and frailty index change types. Logistic regression was also conducted for women and men separately to explore gender differences in the relationships between frailty transition and loneliness. Estimates are shown, adjusted for age and the number of components of baseline physical frailty and others. All the analyses were performed using the statistical package STATA version 15.0. A $p$-value $<0.05$ was deemed statistically significant.

\section{Results}

\section{Descriptive characteristics}

Table 2 summarizes the participant characteristics at baseline during the survey period. In the 2008-2011 waves, the prevalence of often loneliness at baseline was $28.2 \%$, which slightly decreased to $25.8 \%$ in the 2008 2014 waves. Compared with the 6-year follow-up, participants in the 3-year period were older, more likely to be female, had less education, were more likely to live independently, smoked and drank less, and were frailer both in the physical frailty scale and frailty index at baseline.

\section{Frailty transitions}

Table 3 shows the transition in frailty status between the baseline and follow-up. In the 2008 and 2011 waves, nearly half $(49.3 \%)$ of the participants transitioned between different frailty states (robust, prefrail and frail), 2605 (45.3\%) remained robust or prefrail, and 5.3\% remained frail at the follow up. Of the total participants in the 2008 and 2014 waves, more than half $(51.0 \%)$ changed, 1617 (45.6\%) had maintained a robust or prefrail state, and $3.5 \%$ remained in a frail state in the follow-up visit. Overall, the frailty transition was similar between the two periods.

There was a clear difference between the distribution of frailty transition among female and male participants. In the two periods, nearly half of the male participants remained in the robust or prefrail state, whereas about $40 \%$ of the female participants remained at the same level. More female participants worsened in the physical frailty state than male participants, and male participants had a lower prevalence of remaining frail than female participants. However, the female participants showed a higher probability of recovering from greater frailty than the male participants. More than a fifth of the female participants had improved from a greater frailty state in both periods, while 17.3 and $19.5 \%$ of male participants had improved in the two periods, respectively.

\section{Physical frailty transition as an outcome}

The associations between physical frailty transition and loneliness are shown in Table 4. In the remaining robust

Table $\mathbf{2}$ Characteristic of the participants at baseline in two survey periods

\begin{tabular}{|c|c|c|}
\hline & 3-year period (2008-2011) & 6-year period(2008-2014) \\
\hline & $(N=8425)$ & $(N=5245)$ \\
\hline Age, mean (SD) & $82.6(11.0)$ & $79.1(10.1)$ \\
\hline Gender:female,n(\%) & $4607(54.7)$ & $2800(53.4)$ \\
\hline Education year, mean (SD) & $2.4(3.6)$ & $2.6(3.6)$ \\
\hline Residenc:Rural, n(\%) & $5207(61.8)$ & $3319(63.3)$ \\
\hline Living arrangement: independently, n(\%) & $1368(16.2)$ & $843(16.1)$ \\
\hline \multicolumn{3}{|l|}{ Relative economic status, n(\%) } \\
\hline rich & $1467(17.4)$ & $873(16.7)$ \\
\hline so so & $5778(68.7)$ & $3622(69.2)$ \\
\hline poor & $1162(13.8)$ & $740(14.1)$ \\
\hline Current somker, n(\%) & $1710(20.3)$ & $1178(22.5)$ \\
\hline Current drinker, n(\%) & $1670(19.8)$ & $1114(21.2)$ \\
\hline \multicolumn{3}{|l|}{ Loneliness, n(\%) } \\
\hline never & $3262(41.9)$ & $2208(43.8)$ \\
\hline seldom & $2330(29.9)$ & $1532(30.4)$ \\
\hline often & $2195(28.2)$ & $1301(25.8)$ \\
\hline No. of components of frail scale at baseline, mean (SD) & $1.20(1.2)$ & $0.98(1.1)$ \\
\hline Frailty index score at baseline, mean (SD) & $0.13(0.1)$ & $0.11(0.1)$ \\
\hline
\end{tabular}


Table 3 Physical frailty transitions between baseline and follow-up, n (\%)

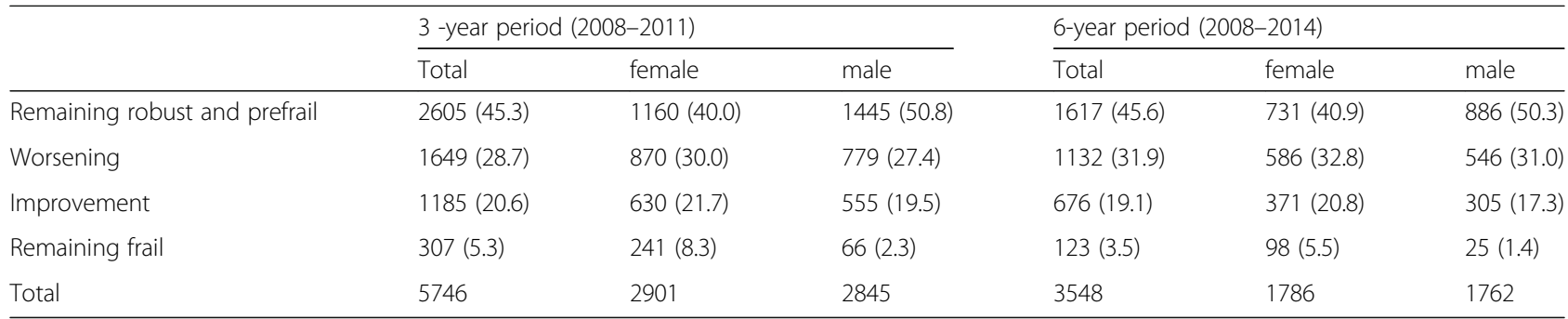

Notes: chi-squared test for physical frailty transitions by gender in 3-year period: $p<0.0001$

chi-squared test for physical frailty transitions by gender in 6-year period: $p<0.0001$

or prefrail group, after adjusting for age, gender, number of components in the frail scale and others at baseline, significant trends in the remaining frail state were associated with a high level of loneliness observed in the 3year period: compared with the never lonely participants, those who often felt lonely were unlikely to remain in the robust or prefrail state $(\mathrm{OR}=0.78,95 \% \mathrm{CI}$ : $0.68-0.91$, $p<0.01)$. In the worsening group, loneliness was a significant risk factor in that a high level of loneliness was associated with worsened frailty states over time years (3-year period: $\mathrm{OR}=1.19,95 \% \mathrm{CI}$ : $1.01-1.41, p<0.05$; 6 year period: $\mathrm{OR}=1.34,95 \% \mathrm{CI}: 1.08-1.66, p<0.01)$. In the improvement group, loneliness showed no significant influence on frailty transition. Loneliness at baseline was positively associated with remaining frail in the 6year period (seldom loneliness: $\mathrm{OR}=2.47$, 95\%CI: $1.25-$ $4.85, p<0.01$ ) but no significant association was shown in the 3-year period.

We also investigated whether the association between loneliness and physical frailty transition differed by gender. Male participants who felt lonely often were negatively related to remaining robust and prefrail (3-year period: $\mathrm{OR}=0.73,95 \% \mathrm{CI}:$ 0.59-0.89, $p<0.01$; 6-year period: $\mathrm{OR}=0.75,95 \% \mathrm{CI}: 0.57-0.99, p<0.05)$ and were

Table 4 Odds ratios $(95 \% \mathrm{Cl})$ for physical frailty transitions and loneliness

\begin{tabular}{|c|c|c|c|c|c|c|c|c|}
\hline & \multicolumn{4}{|c|}{3 -year period (2008-2011) } & \multicolumn{4}{|c|}{ 6-year period (2008-2014) } \\
\hline & $\begin{array}{l}\text { Remaining robust } \\
\text { and prefrail }\end{array}$ & Worsening & Improvement & Remaining frail & $\begin{array}{l}\text { Remaining robust } \\
\text { and prefrail }\end{array}$ & Worsening & Improvement & Remaining frail \\
\hline \multicolumn{9}{|l|}{ Total } \\
\hline never & Ref. & Ref. & Ref. & Ref. & Ref. & Ref. & Ref. & Ref. \\
\hline \multirow[t]{2}{*}{ seldom } & 0.99 & 1.05 & 1.03 & 1.15 & 0.98 & 1.02 & 0.99 & $2.47^{* *}$ \\
\hline & $(0.87-1.13)$ & $(0.90-1.21)$ & $(0.86-1.23)$ & $(0.76-1.73)$ & $(0.83-1.15)$ & $(0.85-1.22)$ & $(0.77-1.26)$ & $(1.25-4.85)$ \\
\hline \multirow[t]{2}{*}{ often } & $0.78^{* *}$ & $1.19^{*}$ & 1.14 & 1.00 & 0.84 & $1.34^{* *}$ & 0.85 & 1.88 \\
\hline & $(0.68-0.91)$ & $(1.01-1.41)$ & $(0.94-1.39)$ & $(0.67-1.51)$ & $(0.70-1.01)$ & $(1.08-1.66)$ & $(0.65-1.12)$ & $(0.93-3.79)$ \\
\hline \multicolumn{9}{|l|}{ Female } \\
\hline never & Ref. & Ref. & Ref. & Ref. & Ref. & Ref. & Ref. & Ref. \\
\hline \multirow[t]{2}{*}{ seldom } & 1.00 & 1.01 & 1.02 & 1.17 & 1.01 & 1.12 & 0.77 & 1.77 \\
\hline & $(0.83-1.21)$ & $(0.82-1.25)$ & $(0.79-1.32)$ & $(0.73-1.87)$ & $(0.80-1.28)$ & $(0.86-1.46)$ & $(0.55-1.08)$ & $(0.83-3.77)$ \\
\hline \multirow[t]{2}{*}{ often } & 0.85 & 1.04 & 1.07 & 0.96 & 0.94 & 1.20 & 0.78 & 1.40 \\
\hline & $(0.69-1.05)$ & $(0.82-1.32)$ & $(0.82-1.40)$ & $(0.60-1.53)$ & $(0.73-1.21)$ & $(0.89-1.60)$ & $(0.55-1.10)$ & $(0.65-3.02)$ \\
\hline \multicolumn{9}{|l|}{ Male } \\
\hline never & Ref. & Ref. & Ref. & Ref. & Ref. & Ref. & Ref. & Ref. \\
\hline \multirow[t]{2}{*}{ seldom } & 0.99 & 1.08 & 1.03 & 1.35 & 0.96 & 0.92 & 1.28 & $12.68^{*}$ \\
\hline & $(0.83-1.18)$ & $(0.88-1.33)$ & $(0.80-1.34)$ & $(0.55-3.32)$ & $(0.77-1.20)$ & $(0.71-1.18)$ & $(0.90-1.82)$ & $(1.66-96.71)$ \\
\hline \multirow[t]{2}{*}{ often } & $0.73^{* *}$ & $1.37^{*}$ & 1.25 & 1.37 & $0.75^{*}$ & $1.54^{* *}$ & 0.94 & 8.89 \\
\hline & $(0.59-0.89)$ & $(1.07-1.75)$ & $(0.93-1.68)$ & $(0.58-3.24)$ & $(0.57-0.99)$ & $(1.13-2.11)$ & $(0.61-1.44)$ & $(0.75-105.30)$ \\
\hline
\end{tabular}

${ }^{* * *} P<0.001,{ }^{* * P} P<0.01,{ }^{*} P<0.05$;

Sample size: 2008-2011 waves: total participants: 5689; for female participants:2866; for male participants:2823;

2011-2014 waves: total participants: 3529; for female participants:1776; for male participants:1753

Notes: Model had been adjusted for age, components number in the frail scale at baseline, residence, education year, living arrangement, relative economic

status, smoking and drinking alcohol at baseline. In total participants, adjustment for gender was also performed 
positively related to worsening frailty (3-year period: $\mathrm{OR}=1.37,95 \% \mathrm{CI}: 1.07-1.75, \quad p<0.05 ; 6$-year period: $\mathrm{OR}=1.54,95 \% \mathrm{CI}: 1.13-2.11, p<0.01)$ in the two survey periods. Loneliness of male participants was also found to be related to remaining frail after 6 years (seldom loneliness: $\mathrm{OR}=12.68$; 95\%CI: $1.66-96.71, p<0.05)$.

\section{Frailty index as an outcome}

Table 5 presents the odds ratios $(95 \% \mathrm{CI})$ for the change in the frailty index and loneliness. Loneliness at baseline was observed to be a protective factor for the improvement in the frailty index only in the 3-year period (seldom loneliness: $\mathrm{OR}=1.42,95 \% \mathrm{CI}: 1.04-1.95, p<0.05$; often loneliness: $\mathrm{OR}=1.50,95 \% \mathrm{CI}$ : $1.08-2.08, p<0.05$ ). Regarding the 6-year period, loneliness at baselines was found to increase the possibility of participants to remain frail (seldom loneliness: $\mathrm{OR}=1.78,95 \% \mathrm{CI}$ : 1.25 $2.55, p<0.01$; often loneliness: $\mathrm{OR}=1.74,95 \% \mathrm{CI}: 1.21-$ $2.50, p<0.01$ ) after 6 years.

Gender differences were also found in the transition type of frailty index and loneliness. Loneliness in male participants was related to remaining frail in the 6-year period (seldom loneliness: $\mathrm{OR}=3.58,95 \% \mathrm{CI}$ : 1.73-7.41, $p<0.001$; often loneliness: $\mathrm{OR}=2.70,95 \% \mathrm{CI}: 1.27-5.76$, $p<0.01$ ), but no significant relationship was found in female participants. A high level of loneliness in female participants was associated with improvement in frailty in the 3-year period $(\mathrm{OR}=1.54 ; 95 \% \mathrm{CI}$ : $1.02-2.31 ; p<$ $0.05)$. The association between loneliness and the frailty index in male participants was the same ash that found in all participants, except that no relationship was observed with the improvement in the frailty index in the 3-year period in male participants with seldom loneliness.

\section{Discussion}

The present study investigated the association between loneliness and frailty transitions. We used the 2008/ 2009, 2011/2012 and 2014 surveys of CLHLS for the analysis, focusing on the difference in the relationships between the male and female participants.

Nearly half of the participants remained in the robust or prefrail state in the follow-up years, regardless of gender. The percentage was higher than that in a previous study in China reporting that $39.6 \%$ of participants remained in the robust or prefrail state in 2002-2005 [42], while the percentage was close to the pooled frailty transition rates among 16 cohorts from 2010 to 2018 [68]. This difference may be due to the baseline time, variations in the follow-up year and measurement of

Table 5 Odds ratios $(95 \%$ Cl) for transition type in frailty index and loneliness

\begin{tabular}{|c|c|c|c|c|c|c|c|c|}
\hline & \multicolumn{4}{|c|}{3 -year period (2008-2011) } & \multicolumn{4}{|c|}{ 6-year period (2008-2014) } \\
\hline & Remaining nonfrail & Worsening & Improvement & Remaining frail & Remaining nonfrail & Worsening & Improvement & Remaining frail \\
\hline \multicolumn{9}{|l|}{ Total } \\
\hline never & Ref. & Ref. & Ref. & Ref. & Ref. & Ref. & Ref. & Ref. \\
\hline \multirow[t]{2}{*}{ seldom } & 1.03 & 0.94 & $1.42^{*}$ & 1.03 & 0.99 & 0.93 & 0.76 & $1.78^{* *}$ \\
\hline & $(0.87-1.20)$ & $(0.79-1.11)$ & $(1.04-1.95)$ & $(0.82-1.30)$ & $(0.82-1.20)$ & $(0.77-1.13)$ & $(0.47-1.22)$ & $(1.25-2.55)$ \\
\hline \multirow[t]{2}{*}{ often } & 0.89 & 0.96 & $1.50^{*}$ & 1.07 & 0.83 & 1.00 & 0.88 & $1.74^{* *}$ \\
\hline & $(0.75-1.05)$ & $(0.80-1.16)$ & $(1.08-2.08)$ & $(0.84-1.36)$ & $(0.67-1.02)$ & $(0.80-1.24)$ & $(0.54-1.42)$ & $(1.21-2.50)$ \\
\hline \multicolumn{9}{|l|}{ Female } \\
\hline never & Ref. & Ref. & Ref. & Ref. & Ref. & Ref. & Ref. & Ref. \\
\hline \multirow[t]{2}{*}{ seldom } & 1.20 & 0.89 & 1.12 & 0.93 & 1.02 & 0.98 & 0.65 & 1.39 \\
\hline & $(0.96-1.49)$ & $(0.71-1.11)$ & $(0.73-1.72)$ & $(0.70-1.23)$ & $(0.78-1.33)$ & $(0.76-1.28)$ & $(0.35-1.22)$ & $(0.92-2.10)$ \\
\hline \multirow[t]{2}{*}{ often } & 0.96 & 0.87 & $1.54^{*}$ & 0.98 & 0.77 & 1.04 & 0.93 & 1.50 \\
\hline & $(0.77-1.21)$ & $(0.68-1.10)$ & $(1.02-2.31)$ & $(0.73-1.31)$ & $(0.58-1.01)$ & $(0.79-1.38)$ & $(0.51-1.67)$ & $(0.99-2.27)$ \\
\hline \multicolumn{9}{|l|}{ Male } \\
\hline never & Ref. & Ref. & Ref. & Ref. & Ref. & Ref. & Ref. & Ref. \\
\hline \multirow[t]{2}{*}{ seldom } & 0.87 & 0.97 & $2.00^{* *}$ & 1.30 & 0.96 & 0.88 & 0.95 & $3.58^{* * *}$ \\
\hline & $(0.69-1.10)$ & $(0.76-1.25)$ & $(1.23-3.24)$ & $(0.86-1.96)$ & $(0.73-1.27)$ & $(0.66-1.16)$ & $(0.46-1.98)$ & $(1.73-7.41)$ \\
\hline \multirow[t]{2}{*}{ often } & 0.84 & 1.05 & 1.41 & 1.35 & 0.94 & 0.95 & 0.77 & $2.70^{* *}$ \\
\hline & $(0.64-1.09)$ & $(0.79-1.39)$ & $(0.81-2.44)$ & $(0.88-2.05)$ & $(0.68-1.30)$ & $(0.68-1.33)$ & $(0.34-1.77)$ & $(1.27-5.76)$ \\
\hline
\end{tabular}

${ }^{* * *} P<0.001,{ }^{* *} P<0.01,{ }^{*} P<0.05$

Sample size: 2008-2011 waves: total participants: 5548; female participants:2833; male participants:2715;

2011-2014 waves: total participants: 3381; for female participants:1737; for male participants:1644

Notes: Model had been adjusted for age, components number of frail scale at baseline, residence, education year, living arrangement, relative economic status, smoking and drinking alcohol at baseline. In total participants, adjustment for gender was also performed 
frailty. Obviously, they may indicate that a window exists during which early interventions may be taken for the elderly to maintain their health status as much as possible. Furthermore, we found that changes from worsening to greater physical frailty tended to be more common than recovering from greater physical frailty, and this pattern of transition was consistent with that in a previous study $[42,68]$. Evidence on gender differences in frailty transition is rare. One study of older people in Hongkong between 2001 and 2003 found that women were less likely to decline in frailty status than men [69], whereas a longitudinal study in San Antonio did not find men to be at higher risk of declining frailty status [70]. Another cohort study in older Italian adults found that women were more likely to progress into worsened physical frailty than men with a mean follow-up of 4.4 years [71]. Our study showed that, compared with men, women were more likely to change frailty status, either improving or worsening, a finding that agrees with a recent systematic review [68] and requires further confirmation by more studies. Thus, frailty interventions may have different efficacies in men and women.

Our study designed four physical frailty transition types-remaining robust or prefrail, improvement, worsening and remaining frail-to ascertain the specific relationship between loneliness and frailty transition. Previous studies have identified loneliness to be related to frailty $[37,38]$. In our study, we found that greater loneliness reduced the possibility of remaining robust or prefrail physical frailty after 3 years, a finding that is consistent with a study in England, in which greater loneliness was found to be associated with increased risk of physical frailty around 4 years later [40]. Additionally, our study used two follow-up periods to validate the relationship. We found that loneliness increased the risk of older people with worsening frailty as well as those remaining frail after 6 years. However but no significant relationship was shown in the 3 -year period. These findings may indicate that loneliness not only increases the possibility of frail in older adults but also increases the likelihood of older adults becoming frailer and chronically frail.

Our study also used another model of frailty, the frailty index, to further verify the results on the relationship between loneliness and frailty transition. We found a clear difference in the association between the levels of loneliness and frailty index between the two survey periods. In the 3-year follow-up, we found that the loneliness at baseline was related to recovering the frailty status in the frailty index. This may be explained by the frailty status at baseline because a severe baseline frailty status is more likely to be improved during the follow-up period. Correspondingly, the relationship between frailty improvement and loneliness was no longer significant in the 6-year follow-up, suggesting that shorter follow-up periods provide more time for older people to change their frailty status. During the 6-year follow-up, loneliness was found to be positively related to remaining in the frail status, but no significant relationship was found in the 3-year follow-up. This finding was supported by a previous study showing that a longer follow-up period was associated with lower rates of remaining in the same frailty state [68]. Additionally, the relationship between frailty index transition and loneliness differed from that between loneliness and physical frailty. For example, loneliness was found not to be associated with worsening in the frailty index, but with worsening physical frailty over time. The broader definition of the frailty index may not have the same risk factors as those of physical frailty [40]. Our findings confirmed this point, and more studies are needed to consolidate the possibility.

Our study also showed that loneliness varied by gender [52]. Low resilience was associated significantly with loneliness and was more pronounced in males [51]. Conversely, high resilience can be a protective factor in facilitating older people to maintain their health status $[72,73]$. Previous research also indicated the stressful impact of loneliness on men, as manifested by increased inflammatory responses [74]. The inflammatory response has a specific physiological basis in the geriatric syndrome of frailty [75], which may be a mechanism underlying gender differences in the relationship between loneliness and physical frailty. Moreover, women tended to have more informal networks, which may lead to more social support, whereas men maintain their social relationships more from the public sphere, which may not always be socially supportive $[59,76]$. Our study indicated that the male participants were more sensitive to the relationship between loneliness and frailty transitions, defined by either physical frailty or the frailty index. Most of the significant relationships observed in the male participants were identical to the findings for all participants. Thus, loneliness in males warrants more attention.

Given that frailty in older adults may be modifiable, our findings have potential implications for both health and social care policy and practice. First, our study provides a picture of the frailty transition among older people in China, highlighting the importance of early interventions for older people to maintain or improve their health statuses, particularly for those in the robust or prefrail state. Second, our study used two frailty models, which demonstrated that the accumulated disadvantages can endanger the elderly in the long term. Frailty management is more than treating specific clinical syndromes and physiological risk factors. Third, previous studies have identified that health behavior and management can be useful to delay or reverse frailty, such as 
physical activity, nutrition and rehabilitation [77]. The relationship between loneliness and frailty transition indicated that psychological treatment is also worthwhile for frailty intervention in older adults. Effective loneliness interventions can delay the progression of frailty. Finally, the findings on gender differences in our study suggest that attention should be given to older men with loneliness and its adverse outcomes.

The study has several limitations. First, among the total participants, $68 \%$ had completed data on the frail scale and $63-67 \%$ on the frail index in the two survey periods. Those who did not complete the questionnaire tended to be frailer and lonelier. Our findings may underestimate the relationship between frailty transition and loneliness. Second, as mentioned earlier, only one question concerned loneliness in CLHLS, likely underrating the prevalence of loneliness. However, a single question concerning loneliness has been widely used in studies and is more feasible for older adults to understand the investigation of loneliness [78, 79]. Finally, mental health variables, such as depression, were not included in the CLHLS.

\section{Conclusion}

Our study examined the association between loneliness and frailty transition among older people in China and attempted to explore gender differences in the relationships. The results revealed that loneliness at baseline may lead to a reduced possibility of remaining in the robust or prefrail frailty state and that greater loneliness is associated with an increased risk of worsening frailty and remaining frail. The association between loneliness and frailty transition differs obviously between men and women. These findings should be considered when designing and implementing health and social care policies for older people.

\section{Abbreviations}

CLHLS: Chinese Longitudinal Healthy Longevity Survey; ADL: Activities of daily living; IADL: Instrument activities of daily living

\section{Acknowledgements}

The authors appreciate the support and comments from all reviewers. The authors would like to thank the Center for Healthy Aging and Development Studies, Peking University for supporting the database.

\section{Authors' contributions}

SS analyzed the data and drafted the manuscript. YX contributed to the research design and review \& editing of manuscript. LC contributed to the study design and methodology. All authors approved the manuscript and this submission.

\section{Funding}

None.

\section{Availability of data and materials}

The datasets that support this article are publicly available from the project of the CLHLS. Questionnaires are free download at website (https://sites. duke.edu/centerforaging/programs/chinese-longitudinal-healthy-longevitysurvey-clhls/survey-documentation/questionnaires/) and the datasets can be obtained after sending a data user agreement to the CLHLS team (https:// sites.duke.edu/centerforaging/programs/chinese-longitudinal-healthylongevity-survey-clhls/data-use-agreement/).

\section{Ethics approval and consent to participate}

Not applicable since the dataset used in the study is publicly available.

\section{Consent for publication}

Not applicable.

\section{Competing interests}

None.

\section{Author details}

${ }^{1}$ School of Social Development and Public Policy, Beijing Normal University, Beijing 100875, China. ${ }^{2}$ Institute of advanced Studies in Humanities and Social Sciences, Beijing Normal University at Zhuhai, Zhuhai 519087, China. ${ }^{3}$ International Business Faculty, Beijing Normal University, Zhuhai 519087, China.

Received: 16 August 2019 Accepted: 17 August 2020

Published online: 24 August 2020

\section{References}

1. WHO. China country assessment report on ageing and health. Switzerland: WHO Press; 2015.

2. Hu Z, Peng X. Household changes in contemporary China: an analysis based on the four recent censuses. J Chinese Sociol. 2015;2(1):9.

3. Gu D, Feng Q, Yeung W-JJ. Reciprocal dynamics of solo-living and health among older adults in contemporary China. J Gerontol Series BPsychological Sci Social Sciences. 2019;74(8):1441-52.

4. Clegg A, Young J, lliffe S, Rikkert MO, Rockwood K. Frailty in elderly people. Lancet. 2013:381(9868):752-62.

5. Gill TM, Gahbauer EA, Allore HG, Han L. Transitions between frailty states among community-living older persons. Arch Intern Med. 2006;166(4):41823.

6. Slaets JPJ. Vulnerability in the elderly: Frailty. Medical Clinics of North America. 2006;90(4):593.

7. Rockwood K, Fox RA, Stolee P, Robertson D, Beattie BL. Frailty in elderly people: an evolving concept. CMAJ. 1994;150(4):489-95.

8. Theou O, Brothers TD, Mitnitski A, Rockwood K. Operationalization of frailty using eight commonly used scales and comparison of their ability to predict all-cause mortality. J Am Geriatr Soc. 2013;61(9):1537-51.

9. Rockwood K, Mitnitski A. Frailty defined by deficit accumulation and geriatric medicine defined by frailty. Clin Geriatr Med. 2011;27(1):17-26.

10. Ensrud KE, Ewing SK, Taylor BC, Fink HA, Stone KL, Cauley JA, Tracy JK, Hochberg MC, Rodondi N, Cawthon PM. Frailty and risk of falls, fracture, and mortality in older women: the study of osteoporotic fractures. J Gerontol A Biol Sci Med Sci. 2007;62(7):744-51.

11. Kojima G. Frailty as a predictor of disabilities among community-dwelling older people: a systematic review and meta-analysis. Disabil Rehabil. 2017; 39(19):1897-908.

12. Hoogendijk EO, Romero L, Sanchez-Jurado PM, Flores Ruano T, Vina J, Rodriguez-Manas L, Abizanda P. A new functional classification based on frailty and disability stratifies the risk for mortality among older adults: the FRADEA study. J Am Med Dir Assoc. 2019.

13. Kojima G. Frailty as a predictor of hospitalisation among communitydwelling older people: a systematic review and meta-analysis. J Epidemiol Community Health. 2016:70(7):722-9.

14. Lambotte D, De Donder L, Van Regenmortel S, Fret B, Dury S, Smetcoren AS, Dierckx E, De Witte N, Verte D, Kardol MJM, et al. Frailty differences in older adults' use of informal and formal care. Arch Gerontol Geriatr. 2018;79: 69-77.

15. Rose M, Pan H, Levinson MR, Staples M. Can frailty predict complicated care needs and length of stay? Intern Med J. 2014;44(8):800-5.

16. Grabovac I, Haider S, Mogg C, Majewska B, Drgac D, Oberndorfer M, Dorner TE. Frailty Status Predicts All-Cause and Cause-Specific Mortality in Community Dwelling Older Adults. J Am Med Directors Assoc. 2019;20(10): 1230.

17. Kojima G. Frailty defined by FRAIL scale as a predictor of mortality: a systematic review and meta-analysis. J Am Med Dir Assoc. 2018;19(6):480-3. 
18. Yang F, Gu D. Predictability of frailty index and its components on mortality in older adults in China. BMC Geriatr. 2016;16.

19. Collard RM, Boter H, Schoevers RA, Voshaar RCO. Prevalence of frailty in community-dwelling older persons: a systematic review. J Am Geriatr Soc. 2012;60(8):1487-92.

20. Cacioppo JT. The growing problem of loneliness. Lancet. 2018;391(10119): 426-6.

21. Hawkley LC, Cacioppo JT. Loneliness matters: a theoretical and empirical review of consequences and mechanisms. Ann Behav Med. 2010;40(2):218-27.

22. Luo Y, Waite LJ. Loneliness and mortality among older adults in China. J Gerontol B Psychol Sci Soc Sci. 2014;69(4):633-45.

23. Luo Y, Hawkley LC, Waite LJ, Cacioppo JT. Loneliness, health, and mortality in old age: a national longitudinal study. Soc Sci Med. 2012;74(6):907-14.

24. Hakulinen C, Pulkki-Raback L, Virtanen M, Jokela M, Kivimaki M, Elovainio M. Social isolation and loneliness as risk factors for myocardial infarction, stroke and mortality: UK biobank cohort study of 479054 men and women. Heart. 2018;104(18):1536-42.

25. Hawkley LC, Thisted RA, Masi CM, Cacioppo JT. Loneliness predicts increased blood pressure: 5-year cross-lagged analyses in middle-aged and older adults. Psychol Aging. 2010;25(1):132-41.

26. Perissinotto CM, Cenzer IS, Covinsky KE. Loneliness in older persons a predictor of functional decline and death. Arch Intern Med. 2012;172(14): 1078-83.

27. Shankar A, McMunn A, Demakakos P, Hamer M, Steptoe A. Social isolation and loneliness: prospective associations with functional status in older adults. Health Psychol. 2017;36(2):179-87.

28. Cacioppo JT, Hawkley LC, Thisted RA. Perceived social isolation makes me sad: 5-year cross-lagged analyses of loneliness and depressive symptomatology in the Chicago health, aging, and social relations study. Psychol Aging. 2010;25(2):453-63.

29. Zhong BL, Chen SL, Tu X, Conwell Y. Loneliness and cognitive function in older adults: findings from the Chinese longitudinal healthy longevity survey. J Gerontol B Psychol Sci Soc Sci. 2017;72(1):120-8.

30. Cacioppo JT, Hawkley LC, Crawford LE, Ernst JM, Burleson MH, Kowalewski RB, Malarkey WB, Van Cauter E, Berntson GG. Loneliness and health: potential mechanisms. Psychosom Med. 2002;64(3):407-17.

31. Hawkley LC, Masi CM, Berry JD, Cacioppo JT. Loneliness is a unique predictor of age-related differences in systolic blood pressure. Psychol Aging. 2006;21(1):152-64.

32. Hawkley LC, Burleson MH, Berntson GG, Cacioppo JT. Loneliness in everyday life: cardiovascular activity, psychosocial context, and health behaviors. J Pers Soc Psychol. 2003;85(1):105-20.

33. Cole SW, Hawkley LC, Arevalo JM, Sung CY, Rose RM, Cacioppo JT. Social regulation of gene expression in human leukocytes. Genome Biol. 2007;8:9.

34. Cole SW, Hawkley LC, Arevalo JMG, Cacioppo JT. Transcript origin analysis identifies antigen-presenting cells as primary targets of socially regulated gene expression in leukocytes. Proc Natl Acad Sci U S A. 2011;108(7):3080-5.

35. Pressman SD, Cohen S, Miller GE, Barkin A, Rabin BS, Treanor JJ. Loneliness, social network size, and immune response to influenza vaccination in college freshmen. Health Psychol. 2005;24(3):297-306.

36. Cooper C, Fielding R, Visser M, van Loon LJ, Rolland Y, Orwoll E, Reid K, Boonen S, Dere W, Epstein S, et al. Tools in the assessment of sarcopenia. Calcif Tissue Int. 2013;93(3):201-10.

37. Herrera-Badilla A, Paticia Navarrete-Reyes A, Amieva H, Alberto Avila-Funes J. LONELINESS IS ASSOCIATED WITH FRAILTY IN COMMUNITY-DWELLING ELDE RLY ADULTS. J Am Geriatr Soc. 2015;63(3):607-9.

38. Hoogendijk EO, Suanet B, Dent E, Deeg DJH, Aartsen MJ. Adverse effects of frailty on social functioning in older adults: results from the longitudinal aging study Amsterdam. Maturitas. 2016;83:45-50.

39. Rockwood K, Howlett SE, MacKnight C, Beattie BL, Bergman H, Hébert R, Hogan DB, Wolfson C, McDowell I. Prevalence, attributes, and outcomes of fitness and frailty in community-dwelling older adults: report from the Canadian study of health and aging. J Gerontol A Biol Sci Med Sci. 2004; 59(12):1310-7.

40. Gale CR, Westbury L, Cooper C. Social isolation and loneliness as risk factors for the progression of frailty: the English longitudinal study of ageing. Age Ageing. 2018;47(3):392-7.

41. Wu C, Smit E, Xue QL, Odden MC. Prevalence and correlates of frailty among community-dwelling Chinese older adults: the China health and retirement longitudinal study. J Gerontol A Biol Sci Med Sci. 2017;73(1):1028.
42. Liu ZY, Wei $Y Z$, Wei LQ, Jiang XY, Wang XF, Shi Y, Hai H. Frailty transitions and types of death in Chinese older adults: a population-based cohort study. Clin Interv Aging. 2018;13:947-56.

43. Gierveld JJ. Tesch-Roemer C: loneliness in old age in eastern and Western European societies: theoretical perspectives. Eur J Ageing. 2012;9(4):285-95.

44. de Jong-Gierveld J, van Tilburg TG, Dykstra PA. Loneliness and social isolation. Cambridge: Cambridge University Press; 2006.

45. Yang K, Victor CR. The prevalence of and risk factors for loneliness among older people in China. Ageing Soc. 2008;28:305-27.

46. Hubbard RE. Sex differences in frailty. Interdisciplinary topics in gerontology and geriatrics. 2015;41:41-53

47. Aartsen M, Jylha M. Onset of loneliness in older adults: results of a 28 year prospective study. Eur J Ageing. 2011;8(1):31-8.

48. Kojima G, lliffe S, Taniguchi Y, Shimada H, Rakugi H, Walters K. Prevalence of frailty in Japan: a systematic review and meta-analysis. J Epidemiology. 2017;27(8):347-53.

49. Gordon EH, Peel NM, Samanta M, Theou O, Howlett SE, Hubbard RE. Sex differences in frailty: a systematic review and meta-analysis. Exp Gerontol. 2017;89:30-40.

50. Ofori-Asenso R, Chin KL, Mazidi M, Zomer E, llomaki J, Zullo AR, Gasevic D, Ademi Z, Korhonen MJ, LoGiudice D, et al. Global Incidence of Frailty and Prefrailty Among Community-Dwelling Older Adults A Systematic Review and Meta-analysis. JAMA Netw Open. 2019;2:8.

51. Zebhauser A, Hofmann-Xu L, Baumert J, Hafner S, Lacruz ME, Emeny RT, Doring A, Grill E, Huber D, Peters A, et al. How much does it hurt to be lonely? Mental and physical differences between older men and women in the KORA-age study. Int J Geriatric Psychiatry. 2014;29(3):245-52.

52. Zhou Z, Wang P, Fang Y. Loneliness and the risk of dementia among older Chinese adults: gender differences. Aging Ment Health. 2018;22(4):519-25.

53. Zeng Y, Poston DL Jr, Vlosky DA, Gu D. Healthy longevity in China: demographic, socioeconomic, and psychological dimensions; 2008.

54. Zeng $Y$. Towards deeper research and better policy for healthy aging --using the unique data of Chinese longitudinal healthy longevity survey. China economic journal. 2012;5(2-3):131-49.

55. Patterson AC, Veenstra G. Loneliness and risk of mortality: a longitudinal investigation in Alameda County, California. Soc Sci Med. 2010;71(1):181-6.

56. Savikko N, Routasalo P, Tilvis RS, Strandberg TE, Pitkala KH. Predictors and subjective causes of loneliness in an aged population. Arch Gerontol Geriatr. 2005;41(3):223-33.

57. Theeke LA. Predictors of loneliness in US adults over age sixty-five. Arch Psychiatr Nurs. 2009;23(5):387-96.

58. Tilvis RS, Pitkala KH, Jolkkonen J, Strandberg TE. Social networks and dementia. Lancet. 2000;356(9223):77-8.

59. Pinquart $M$, Sorensen $S$. Influences on loneliness in older adults: a metaanalysis. Basic Appl Soc Psychol. 2001;23(4):245-66.

60. Abellan van Kan G, Rolland YM, Morley JE, Vellas B. Frailty: toward a clinical definition. J Am Med Dir Assoc. 2008;9(2):71-2.

61. Aprahamian I, Cezar NOC, Izbicki R, Lin SM, Paulo DLV, Fattori A, Biella MM, Jacob Filho W, Yassuda MS. Screening for frailty with the FRAIL scale: a comparison with the phenotype criteria. J Am Med Dir Assoc. 2017;18(7): 592-6.

62. Morley JE, Malmstrom TK, Miller DK. A simple frailty questionnaire (FRAIL) predicts outcomes in middle aged African Americans. J Nutr Health Aging. 2012;16(7):601-8.

63. Searle SD, Mitnitski A, Gahbauer EA, Gill TM, Rockwood K. A standard procedure for creating a frailty index. BMC Geriatr. 2008;8:24.

64. Gu D, Dupre ME, Sautter J, Zhu H, Liu Y, Yi Z. Frailty and mortality among Chinese at advanced ages. J Gerontol B Psychol Sci Soc Sci. 2009;64(2):279-89.

65. Goggins WB, Woo J, Sham A, Ho SC. Frailty index as a measure of biological age in a Chinese population. J Gerontol A Biol Sci Med Sci. 2005;60(8):1046-51.

66. Zhu A, Yan L, Wu C, Ji JS. Residential Greenness and Frailty Among Older Adults: A Longitudinal Cohort in China. J Am Med Dir Assoc. 2020;21(6): 759-65 e752.

67. Gu D, Yang F, Sautter J. Socioeconomic status as a moderator between frailty and mortality at old ages. BMC Geriatr. 2016;16:151.

68. Kojima G, Taniguchi Y, lliffe S, Jivraj S, Walters K. Transitions between frailty states among community-dwelling older people: a systematic review and meta-analysis. Ageing Res Rev. 2019;50:81-8.

69. Lee JS, Auyeung TW, Leung J, Kwok T, Woo J. Transitions in frailty states among community-living older adults and their associated factors. J Am Med Dir Assoc. 2014;15(4):281-6. 
70. Espinoza SE, Jung I, Hazuda H. Frailty transitions in the San Antonio longitudinal study of aging. J Am Geriatr Soc. 2012;60(4):652-60

71. Trevisan C, Veronese N, Maggi S, Baggio G, Toffanello ED, Zambon S, Sartori L, Musacchio E, Perissinotto E, Crepaldi G, et al. Factors influencing transitions between frailty states in elderly adults: the Progetto Veneto Anziani longitudinal study. J Am Geriatr Soc. 2017;65(1):179-84.

72. Ferrucci L, Giallauria F, Schlessinger D. Mapping the road to resilience: novel math for the study of frailty. Mech Ageing Dev. 2008;129(11):677-9.

73. Cesari M, Prince M, Thiyagarajan JA, De Carvalho IA, Bernabei R, Chan P, Gutierrez-Robledo LM, Michel JP, Morley JE, Ong P, et al. Frailty: an emerging public health priority. J Am Med Dir Assoc. 2016;17(3):188-92.

74. Hermes GL, Rosenthal L, Montag A, McClintock MK. Social isolation and the inflammatory response: sex differences in the enduring effects of a prior stressor. Am J Phys Regul Integr Comp Phys. 2006;290(2):R273-82.

75. Walston J, McBurnie MA, Newman A, Tracy RP, Kop WJ, Hirsch CH Gottdiener J, Fried LP. Cardiovascular Hlth study I: frailty and activation of the inflammation and coagulation systems with and without clinical comorbidities - results from the cardiovascular health study. Arch Intern Med. 2002;162(20):2333-41.

76. Stevens N. Gender and adaptation to widowhood in later life. Ageing Soc. 1995;15:37-58.

77. Puts MTE, Toubasi S, Andrew MK, Ashe MC, Ploeg J, Atkinson E, Ayala AP, Roy A, Monforte MR, Bergman $\mathrm{H}$, et al. Interventions to prevent or reduce the level of frailty in community-dwelling older adults: a scoping review of the literature and international policies. Age Ageing. 2017;46(3):383-92.

78. Victor C, Grenade L, Boldy D. Measuring loneliness in later life: a comparison of differing measures. Rev Clin Gerontol. 2006;15(01):63.

79. Jylha M. Old age and loneliness: cross-sectional and longitudinal analyses in the Tampere longitudinal study on aging. Can J Aging-Revue Canadienne Du Vieillissement. 2004;23(2):157-68.

\section{Publisher's Note}

Springer Nature remains neutral with regard to jurisdictional claims in published maps and institutional affiliations.

Ready to submit your research? Choose BMC and benefit from:

- fast, convenient online submission

- thorough peer review by experienced researchers in your field

- rapid publication on acceptance

- support for research data, including large and complex data types

- gold Open Access which fosters wider collaboration and increased citations

- maximum visibility for your research: over $100 \mathrm{M}$ website views per year

At $\mathrm{BMC}$, research is always in progress.

Learn more biomedcentral.com/submissions 